\title{
Intervenciones del arquitecto Francisco Ferriol en Alcañices (Zamora) a principios del siglo $X X$
}

\section{Works of the Architect Francisco Ferriol in Alcañices (Zamora) at the Beginning of the Twentieth Century}

Artículo recibido el 3I de julio de 2020; devuelto para revisión el 2I de septiembre de 2020; aceptado el I de febrero de 202I; https://doi.org/IO.2220I/iie.I8703062e.202I.II9.2766

José Luis Hernández Luis Universidad Nacional de Educación a Distancia (UNED), España, jlhernandez@zamora.uned.es, http://orcid.org/oooo-oooI-9330-7674

Líneas de investigación Patrimonio cultural y arquitectura contemporánea.

Lines of reserach Cultural heritage and contemporary architecture.

Publicación más relevante "La torre de la iglesia de Carbajales de Alba (Zamora) y los comienzos del hierro en la arquitectura zamorana", Boletín del Seminario de Arte y Arqueología, núm. 83 (2017): 277-290, https://doi.org/I0.24197/ bsaaa.83.2017.277-290.

Resumen La arquitectura ha sido utilizada a lo largo de la historia como herramienta de representación del poder político, económico y social. En muchos casos recurriendo a destacados profesionales. El azaroso proceso de gestación de varios inmuebles diseñados a principios del siglo $\mathrm{xx}$ en Alcañices (Zamora) por Francisco Ferriol, introductor del modernismo en la provincia, muestra las dificultades de la administración pública española para dotarse de unas infraestructuras dignas, que repercutiesen en una imagen moderna, atractiva y respetable. Al mismo tiempo, la investigación pone de relieve la utilización de la vivienda burguesa como elemento de diferenciación social, mediante la implantación de una arquitectura moderna y urbana en un contexto rural tradicional.

Palabras clave Arquitectura; representación; Alcañices (Zamora, España); siglo xx; Francisco Ferriol.

Abstract Architecture has been used throughout history as a tool for representing political, economic and social power. In many cases resorting to prominent professionals. The risky process of gestation of several buildings designed at the beginning of the 2oth century in Alcañices (Zamora) 
by Francisco Ferriol, introducer of modernism in the province, shows the difficulties of the Spanish public administration to equip itself with decent infrastructure, which would have an impact on a modern, attractive and respectable image. At the same time, the research highlights the use of bourgeois housing as an element of social differentiation, through the implantation of modern and urban architecture in a traditional rural context.

Keywords Architecture; representation; Alcañices (Zamora, Spain); 2oth century; Francisco Ferriol. 


\section{JOSÉ LUIS HERNÁNDEZ LUIS}

UNIVERSIDAD NACIONAL DE EDUCACIÓN A DISTANCIA (UNED), ESPAÑA

\section{Intervenciones del arquitecto Francisco Ferriol en Alcañices (Zamora) a principios del siglo $X X$}

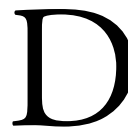
esde su origen, la arquitectura ha servido al poder constituido para comunicar autoridad e infundir respeto. Tras la Revolución Industrial, su función simbólica ya no se limitará al poder político o religioso; también la burguesía y las grandes empresas utilizarán con frecuencia la arquitectura para transmitir sus valores y diferenciarse. Unos y otros recurrirán a los más afamados profesionales, cuya notoriedad amplifica el simbolismo de las construcciones.

Lo arriba expuesto sucede tanto con los edificios públicos como con los privados. Entre los primeros, la escuela presenta un gran simbolismo, pues ha servido en época contemporánea como soporte de la imagen del Estado y aglutinante de la conciencia colectiva de los pueblos. ${ }^{I}$ Respecto a los edificios privados, como la vivienda, la arquitectura ha sido un elemento decisivo en todo Occidente para la construcción de una identidad social diferenciada. ${ }^{2}$

I. Agustín Escolano, "La arquitectura como programa: espacio-escuela y curriculum", Historia de la Educación, núms. I2 y I3 (I993-1994): I03-I04, I07-IO9 y III, https://revistas.usal.es/ index.php/0212-0267/article/view/IOIı/1053I (consultado en abril de 2020); Antonio Viñao Frago, "Del espacio escolar y la escuela como lugar: propuestas y cuestiones", Historia de la Educación, núms. I2 y I3 (1993-1994): 19, https://revistas.usal.es/index.php/0212-0267/article/ view/ı1367/II786 (consultado en abril de 2020).

2. Nieves Basurto y María Jesús Pacho, "Ascenso social y espacio doméstico en Bilbao. La arquitectura como escenografía del poder", Historia Contemporánea, núm. 39 (2009): 483-484, 


\section{DOI: https://doi.org/10.22201/iie.18703062e.2021.119.2766}

404

JOSÉ LUIS HERNÁNDEZ LUIS

En las líneas que siguen nos aproximaremos al funcionamiento de estos mecanismos simbólicos, por medio de varios edificios (principalmente una escuela y una vivienda), muy relacionados en su origen, que contribuyeron a transmitir una imagen de la administración pública y a construir la identidad burguesa de una familia, al insertar formas y técnicas arquitectónicas modernas en un entorno rural como el Aliste de principios del siglo xx. Tales intervenciones se debieron al arquitecto Francisco Ferriol, introductor del modernismo en Zamora, del que conocemos muy bien su labor en la capital y poco de sus trabajos en el resto de la provincia. ${ }^{3}$

\section{La escuela pública. Antecedentes}

Tras el desastre de I898 se buscó remedio a la decadencia de España en la educación, factor fundamental de modernización. Inspirados en el caso francés, los gobiernos que se suceden a principios de la nueva centuria pretenden convertir la escuela en un elemento de construcción nacional, aunque los resultados no fueron los esperados por falta de medios y consenso político. ${ }^{4}$ Entre las muchas medidas adoptadas destaca la construcción de nuevas escuelas por parte del Estado y algunos municipios. 5

487 y 504, https://www.ehu.eus/ojs/index.php/HC/article/view/2376/1976 (consultado en abril de 2020).

3. Francisco Ferriol Carreras nace en Barcelona en 187i. Estudia en la Escuela de Arquitectura de dicha ciudad, donde se titula en I894. Antes de acabar sus estudios colabora con el arquitecto Luis Doménech i Montaner en la conversión del restaurante de la Exposición Universal de I888, en el Museo de Historia y en la remodelación del Seminario de Comillas (Cantabria). Desde su titulación hasta la llegada a Zamora proyecta varios edificios de viviendas en la ciudad condal. Se traslada a la capital del Duero en 1907 como arquitecto municipal. En 1916 obtiene la plaza de arquitecto provincial de Cádiz y se marcha de Zamora, por problemas de salud. Al poco de llegar a Cádiz renuncia por ser nombrado arquitecto de la Cámara de la Propiedad Urbana de Barcelona. Álvaro Ávila de la Torre, "Francesc Ferriol, un arquitecto modernista entre Barcelona y Zamora”, Materia, núms. 6-7 (2006): 235, 244-245 y 254, https://revistes.ub.edu/index. $\mathrm{php} / \mathrm{materia/article/view/II477/I4290} \mathrm{(consultado} \mathrm{en} \mathrm{abril} \mathrm{de} \mathrm{2020).} \mathrm{Este} \mathrm{mismo} \mathrm{autor} \mathrm{prepara}$ una monografía sobre el arquitecto, Francisco Ferriol Carreras, arquitecto (I871-1946) (en prensa).

4. Juan Manuel Fernández Soria, "A propósito del 98: modernidad, Estado y educación (España I898-1923), Revista de Educación, núm. 317 (1998): 207, 217 y 225, http://www.educacionyfp.gob.es/dam/jcr:a62b2dcc-7a36-40fd-8d95-93d3ea76f5b4/re3171200465-pdf (consultada en abril de 2020).

5. Antonio Viñao Frago, "El espacio escolar. Introducción”, Historia de la Educación, núms. I2 
La villa de Alcañices, capital de la zamorana comarca de Aliste, no era una excepción en este desastroso panorama general. Cerca de 1882 no se disponía de un edificio destinado a la enseñanza primaria, a pesar del carácter de capital de partido. Se impartía docencia en un local de alquiler (niñas) y en un edificio municipal (niños), ambos de insuficiente capacidad y salubridad. Por ello, el ayuntamiento acordó construir una escuela para niños y niñas (además de viviendas para los maestros), y encargó el proyecto al arquitecto provincial, Segundo Viloria, que por limitaciones presupuestarias se ciñe a lo meramente indispensable. ${ }^{6}$

El municipio no podía sufragar todo el costo. Se estimaba que podía aportar la cuarta parte mediante la venta del edificio destinado a escuela de niños y la vivienda para su maestro, la prestación personal de los vecinos y el presupuesto ordinario municipal, en una o varias anualidades. El consistorio solicitó al Ministerio de Fomento que sufragara el resto. ${ }^{7} \mathrm{Al}$ final, el proyecto no saldrá adelante, puesto que en 1900 se proyectaban reparaciones en el edificio que ocupaba la escuela de niños y en la vivienda del docente. ${ }^{8}$

Y así llegamos al edificio que nos interesa. En el pleno del ayuntamiento del 3 de febrero de 1908 el alcalde, Francisco Corcobado, habida cuenta de las importantes sumas gastadas en años anteriores en primera enseñanza, propone que se abandone otro proyecto anterior de construir una escuela en una de las casas del marqués de Alcañices y que se construya una de nueva planta. La corporación, en vista de no contar el municipio con escuela de niñas y estar en vergonzosa ruina la de nińos, se mostró de acuerdo en construir un nuevo edificio en el solar inmediato al Campo de la Era por ser un lugar que reunía

y I3 (I993-I994): I3-I5, https://revistas.usal.es/index.php/O2I2-0267/article/view/IOII3/IO529 (consultada en abril de 2020). Se calcula que hacia 1908 más de un millón de potenciales alumnos no disponían de un puesto escolar. Respecto a la situación de los edificios, en 1903 algo más del 20 por ciento de las escuelas públicas estaban cerradas por no contar con las preceptivas condiciones. Ramón López Martín, "La construcción y creación de escuelas en la Espańa del primer tercio del siglo xx", Historia de la Educación, núm. I6 (1997): 67-69, 75, 84 y 90, https://revistas. usal.es/index.php/0212-0267/article/view/I0528/I0942 (consultado en abril de 2020).

6. El consistorio escogió un solar aislado, frente al costado izquierdo del convento de San Francisco (plazuela de San Andrés), bien comunicado y con buenas condiciones higiénicas. El edificio que se planteaba tenía un cuerpo central para las entradas y viviendas, junto a dos laterales para las aulas de cada sexo, dejándose parte de los solares para patios de recreo. Archivo Municipal de Alcañices (AMA), caja I35, carpeta I, memoria descriptiva y presupuesto.

7. AMA, caja 135, carpeta 2, fols. 9-Ior.

8. AMA, caja 135 , carpeta 3. 


\section{DOI: https://doi.org/10.22201/iie.18703062e.2021.119.2766}

406

JOSÉ LUIS HERNÁNDEZ LUIS

condiciones de higiene y salubridad, aunque no podría materializarse sin contar, al menos, con una ayuda estatal de 50 por ciento. ${ }^{9}$

Recordemos que la construcción y conservación de las escuelas públicas estaba a cargo de los ayuntamientos. Asimismo, para resolver los problemas administrativos y adaptarse mejor a las condiciones de cada lugar, el expediente era tramitado por los consistorios; el Estado se limitaba a su comprobación y resolución. Ésta se producía en forma de subvención, que variaba en función del presupuesto de la administración local y de su inversión en educación pública. ${ }^{10}$

El ayuntamiento de la villa encargó el proyecto a Francisco Ferriol, arquitecto municipal de Zamora, que lo concluyó en marzo de 1908. La obra se subastó en agosto y fue adjudicada en 69,I6I pesetas. El plazo de ejecución de las obras se fijaría en un año a partir de la firma del contrato. ${ }^{\text {II }}$

La concesión de una ayuda por parte del Estado allanó el camino para la construcción de la nueva escuela. Por real decreto del 5 de junio se concedía al ayuntamiento para este propósito la subvención de 34,580 pesetas, es decir, 50 por ciento de lo presupuestado, con cargo a los ejercicios económicos I908-I9II. ${ }^{\mathrm{I2}}$ Pero, por diversas razones, la terminación del edificio se retrasó. Todavía en febrero de I9II se arrendaban dos locales para escuelas en tanto se concluía la obra. Finalmente, el nuevo grupo escolar entró en funcionamiento durante el curso I9II-I9I2. ${ }^{\text {I3 }}$

\section{La escuela de Ferriol}

El edificio se proyectó siguiendo la Instrucción técnico-higiénica relativa a la construcción de escuelas que apareció publicada en la Gaceta de Madrid el 29 de abril de 1905 . Esta norma formaba parte de un plan para la reforma pedagógica

9. AMA, lib. 228, fols. IIv-I2r.

Iо. Gaceta de Madrid (GM) (29 de septiembre de 1904): I097-I098, https://www.boe.es/ datos/pdfs/BOE//1904/27I/Aoro97-0I099.pdf (consultado en junio de 2020); (29 de abril de I905): 405-406 (consultado en junio de 2020), https://www.boe.es/datos/pdfs/BOE//1905/II9/ Ao0405-00406.pdf (consultado en junio de 2020).

II. AMA, caja I35, carpeta 4, certificación de acuerdo, acta de subasta y fols. 28r y 35r.

I2. GM (6 de junio de I908), III4, https://www.boe.es/datos/pdfs/BOE//I908/I58/AorII4oIII4.pdf (consultado en junio de 2020).

I3. AMA, lib. 230, fol. 47 y lib. 23I, fol. $20 v$. 


\section{DOI: https://doi.org/10.22201/iie.18703062e.2021.119.2766}

INTERVENCIONES DE FRANCISCO FERRIOL EN ALCAÑICES

de la enseñanza en España. Regulaba, de forma completa y moderna, aspectos como el emplazamiento, la orientación, el tamaño, los materiales de construcción, los espacios, la ventilación, la iluminación, la calefacción y el mobiliario de los edificios escolares. ${ }^{\mathrm{I}}$

La Instrucción establecía que a la hora de elegir el emplazamiento fuesen tenidos en cuenta criterios no sólo higiénicos, sino también morales. Por ello, se rechazaban las vecindades perniciosas para los nińos y se consideraban factores como el tráfico. Eran los postulados de la Institución Libre de Enseñanza. Con ellos pretendían garantizar la educación ambiental y moral de los alumnos. ${ }^{15} \mathrm{Al}$ seguir estas premisas, la escuela se ubicó al extremo de la población, en un lugar seco y soleado, con la fachada principal orientada hacia el mediodía. ${ }^{16}$ Se trataba de un edificio completamente exento.

El arquitecto diseñó una construcción "sólida, sencilla y de vistoso aspecto”, según sus propias palabras. Para lograr mayor economía se emplearían los materiales locales, en especial los sillares de granito, la mampostería de pizarra, enlucida con una mezcla de cemento y arena, así como la madera y la teja común para las cubiertas. Debido a la carencia de ladrillos, serán utilizados sólo para la tabiquería interior. ${ }^{17}$

El proyecto contemplaba un cuerpo central, dos alas laterales y dos cuerpos extremos unidos a éstas (fig. I). El cuerpo central acogería una gran sala destinada a biblioteca popular y museo escolar. Por detrás se situaban, completamente aislados, los retretes, urinarios y lavabos, a razón de uno por cada I5 alumnos. Las alas laterales eran iguales, la de la derecha para los nińos y

I4. AMA, caja 135, carpeta 4, fols. 20-2Ir. GM (29 de abril de 1905): 406-408, https://www.boe. es/datos/pdfs/BOE//I905/II9/A00405-00406.pdf (consultado en junio de 2020). La legislación la impulsó Carlos María Cortezo, quien desempenó el cargo de ministro de Instrucción Pública entre abril y junio de 1905 . Cortezo era un médico vinculado al krausismo, cofundador de la Sociedad Española de Higiene (I882) y representante de Espańa en diversas conferencias internacionales sobre esta materia. Esteban Rodríguez Ocaña, "Carlos María Cortezo y Prieto", http://dbe.rah.es/biografias/5153/carlos-maria-cortezo-y-prieto (consultado en mayo de 2020).

I5. Viñao, "Del espacio escolar", 30; Escolano, "La arquitectura como programa”, IO3-IO4. En palabras de Rodríguez Méndez, en arquitectura escolar los institucionistas "sugieren modelos ideales [de origen europeo], pero no imponen soluciones concretas". Véase Francisco Javier Rodríguez Méndez, "La Institución Libre de Enseñanza y la arquitectura escolar", Historia de la Educación, núm. 25 (2006): 469-470, https://revistas.usal.es/index.php/0212-0267/article/ view/ıII9o/ı16I2 (consultado en septiembre de 2020).

I6. AMA, caja 135 , carpeta 4 , fol. 22.

17. AMA, caja 135, carpeta 4, fols. 22v-23r. 


\section{DOI: https://doi.org/10.22201/iie.18703062e.2021.119.2766}

\section{8}

JOSÉ LUIS HERNÁNDEZ LUIS

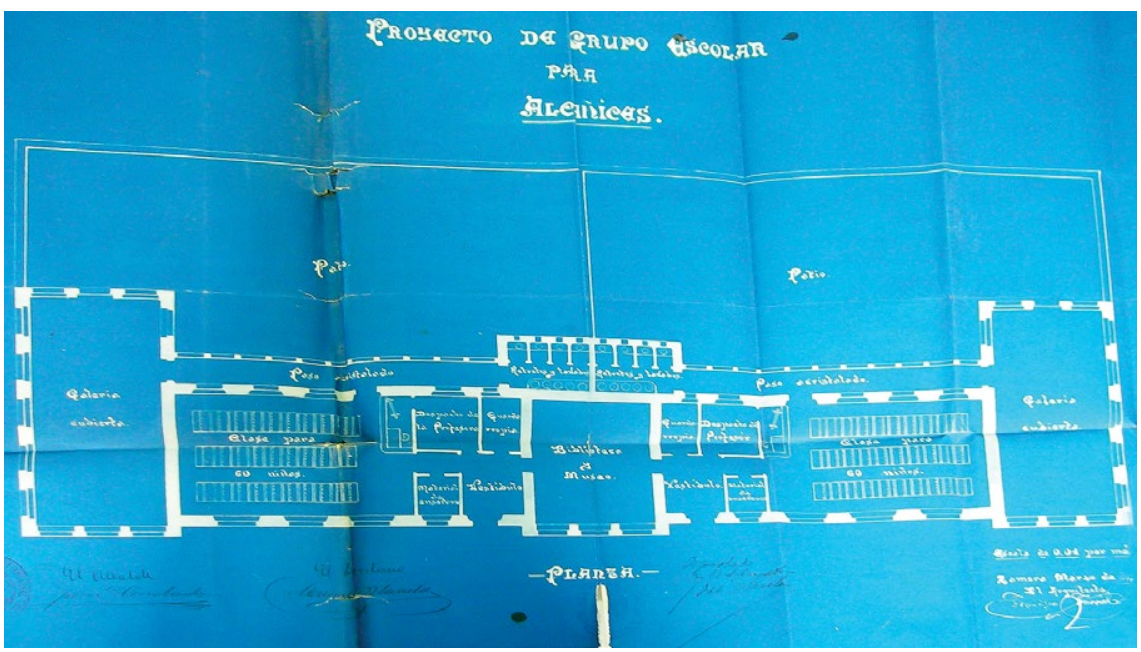

I. Francisco Ferriol, "Proyecto de grupo escolar para Alcañices (planta)", marzo de 1908. AMA, caja I35, carpeta 4 , s. f.

la opuesta para las niñas. Constaban cada una de vestíbulo concebido como sala de espera para los encargados de recoger a los alumnos, un guardarropa con perchas para los abrigos y gorras, un cuarto para el material de enseñanza, un pequeño despacho para el profesor y, por último, las respectivas aulas, con capacidad para 60 alumnos. Dichas aulas dispondrían de una superficie de I.25 metros por alumno y una altura de 4 metros. Detrás de las aulas trazaba un corredor acristalado que conducía a los retretes y al patio o galería cubierta. Éstas se levantaban en cada extremo, con 150 metros cuadrados de superficie, para solaz de los alumnos cuando el tiempo no permitiese el juego al aire libre. El resto del solar se dejaría como gran patio de arena, partido en dos mitades, con árboles que proporcionaran sombra y sus respectivas fuentes de agua potable. ${ }^{18}$

El edificio responde al momento en que se inicia el tránsito en España de la escuela-aula a la escuela-colegio, vigente hasta bien entrada la segunda mitad del siglo xx, con retraso respecto a otros países. Se ha incrementado el número de espacios para diferentes funciones. No obstante, todavía contempla

I8. AMA, caja I35, carpeta 4, fol. 23. 


\section{DOI: https://doi.org/10.22201/iie.18703062e.2021.119.2766}

INTERVENCIONES DE FRANCISCO FERRIOL EN ALCAÑICES

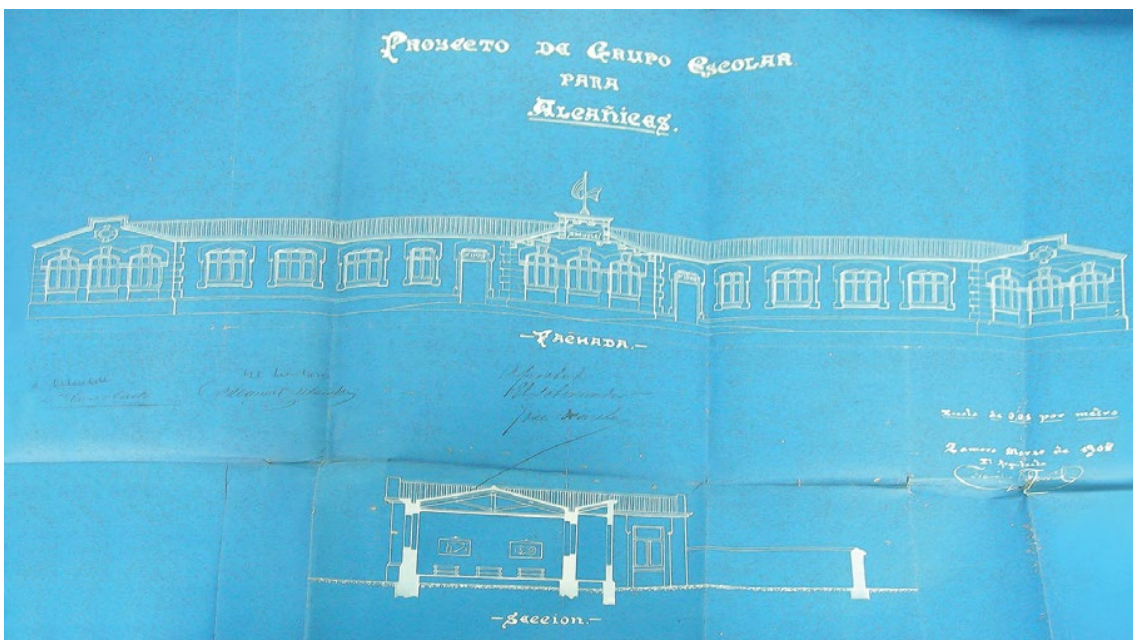

2. Francisco Ferriol, "Proyecto de grupo escolar para Alcañices (fachada y sección)", marzo de 1908. AMA, caja 135, carpeta 4.

un aula única (por sexo) para concentrar todas las edades, no aulas diferentes por cursos. ${ }^{19}$

Muy atento a las condiciones higiénicas, Ferriol planteó una ventilación natural, al abrir puertas y ventanas durante los descansos y una vez terminadas las clases. También el proyecto tenía en cuenta la importancia de la iluminación para prevenir enfermedades de la vista (como la miopía), y estimular el aprendizaje. La luz debía ser constante, uniforme, difusa, no reflejada y con bastante inclinación. Para ello se concibieron amplios ventanales, bilaterales, con un antepecho a metro y medio (fig. 2). Por último, el edificio dispondría de una alcantarilla construida con material hidráulico, que desaguaba en un depósito construido en el campo enarenado. ${ }^{20}$

Sin embargo, el edificio alzado no sigue al pie de la letra el proyecto. ${ }^{2 \mathrm{E}} \mathrm{El}$ resultado final presenta una notable reducción de las dimensiones de la plan-

19. Viñao, "Del espacio escolar", 49-52 y 70.

20. AMA, caja I35, carpeta 4, fols. 24 y 3IV-32r.

2I. En el pleno del 7 de junio de 1909 se acusa al contratista de las obras de no seguir las condiciones y el plano contemplados en el proyecto. El alcalde respondió que no era competencia del ayuntamiento, pues el arquitecto que había elaborado el proyecto continuaba al frente de 


\section{DOI: https://doi.org/10.22201/iie.18703062e.2021.119.2766}

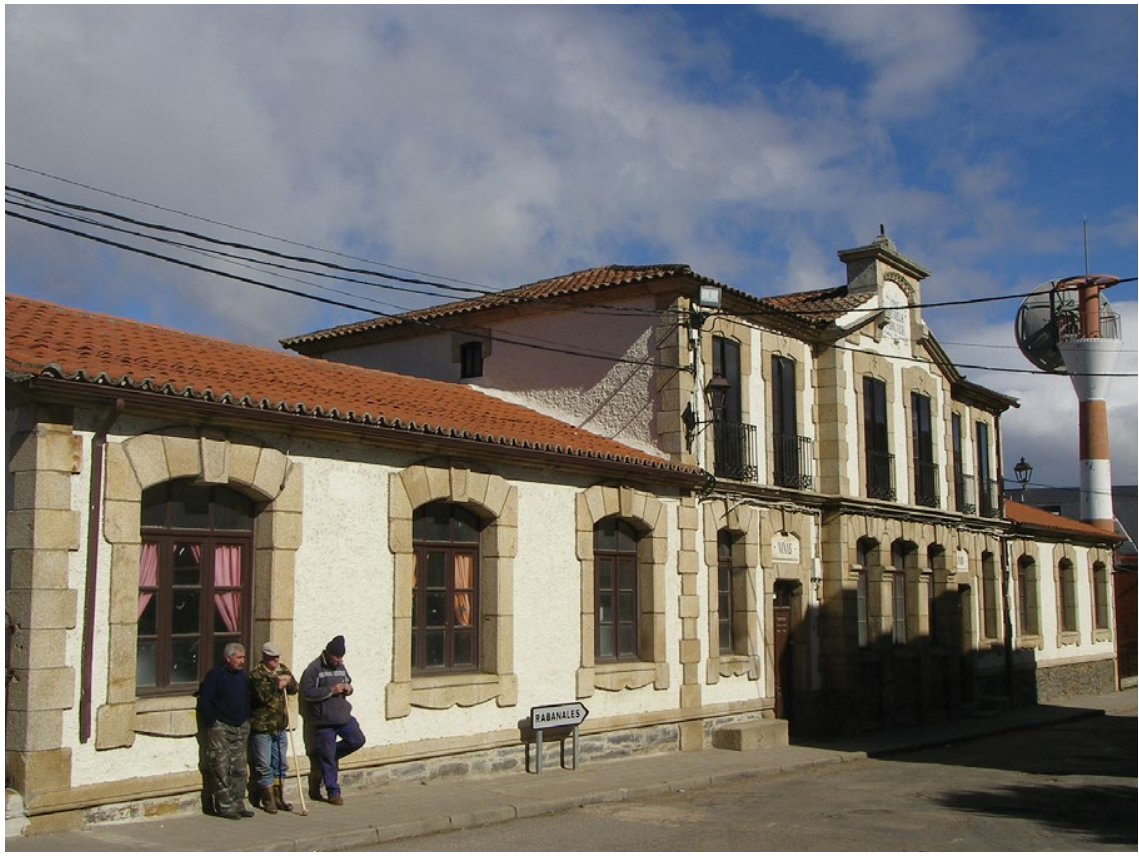

3. Vista actual del edificio escolar, con las alas reducidas para las clases y el primer piso para vivienda de los docentes. Foto del autor.

ta. Así pues, se eliminaron las galerías cubiertas laterales y la galería acristalada trasera. El inmueble quedó reducido a un cuerpo central, al que se adosaban por cada lado sendas aulas para nińos y niñas. Los baños ya no eran una prolongación del cuerpo central, sino que formaban parte de él, y compartían espacio con el acceso a las viviendas de los maestros y dependencias auxiliares de las aulas. Además, se construyó un primer piso sobre el cuerpo central para vivienda de los maestros (fig. 3), un esquema que había sido muy habitual en las construcciones escolares hasta la promulgación de la legislación de Cortezo (véase n. I7). ${ }^{22}$

las obras. AMA, lib. 229, fol. I4v. En este sentido, la cláusula diez de las condiciones del proyecto facultaba al arquitecto a introducir cambios en el proyecto, si fuere necesario, y se redactaba un modificando que no se ha conservado en el archivo municipal. AMA, caja 135, carpeta 4, fol. 28. 22. AMA, lib. 230, fols. 28v, 33 y 37v. Tanto el Real Decreto (art. I8. $2^{\mathrm{a}}$ ), como la Instrucción (epígrafe V) y la Real Orden (art. $7^{\circ}$ ), publicados el 29 de abril de 1905 , insistían en que no se incluyesen en los edificios escolares viviendas para los profesores por cuestiones higiénicas, 


\section{La Casa Corcobado \\ Promoción de la vivienda}

Todo apunta a que la presencia de Francisco Ferriol al frente de las obras de la escuela de Alcañices fue aprovechada por Manuel Corcobado Losada, hermano del alcalde promotor del grupo escolar, ${ }^{23}$ para encargarle el proyecto de su nueva vivienda en la plaza mayor de la villa. Manuel Corcobado aparece en la matrícula industrial de i9io como titular de un negocio de ferretería. ${ }^{24}$

El solar donde se levanta el inmueble ya figuraba en el Padrón de Edificios y Solares de I894-I895 a nombre de Florentino Corcobado Sánchez, padre del

económicas y pedagógicas. GM (29 de abril de 1905): 405-408, https://www.boe.es/buscar/ gazeta.php (consultado en junio de 2020). No obstante, el estudio de la propia normativa sobre construcción de escuelas refleja cambios de criterio respecto a la presencia de vivienda para los maestros. Por ejemplo, el Real Decreto del 26 de septiembre de 1904 que inicia las disposiciones en esta materia, admitía que se pudiera autorizar la construcción de vivienda para los profesores cuando lo exigiesen las necesidades económicas u otras causas justificadas (art. $4^{\circ}$ ). Más adelante, durante el periodo de construcción de nuestro edificio aparece una normativa que recordaba la obligatoriedad de las disposiciones señaladas en la instrucción de abril de 1905, ya señalada, que prohibía expresamente las viviendas en los edificios escolares. Las normas posteriores atribuyen la negligencia en el cumplimiento a las juntas provinciales y locales de Instrucción Pública, prueba evidente de que se vulneraban con frecuencia. GM (29 de septiembre de 1904): I098, https://www.boe.es/datos/pdfs/воE//1904/27I/Aoro97-oro99.pdf (consultado en junio, 2020); GM (6 de mayo de 1909): II55-II56, https://boe.es/datos/pdfs/BOE//1909/126/ Aori55-0II56.pdf (consultado en junio de 2020).

23. En las matrículas industriales de i9ro y i9ı el alcalde Francisco Corcobado Losada consta como titular de un comercio de mercería y una fábrica de gaseosas. Archivo Histórico Provincial de Zamora (AHPZa), Fondo antiguo, leg. 305, exp. 3 y leg. 369, exp. 3. Parece que también se dedicaba a la venta de armas, especialmente escopetas de caza. El Correo de Zamora (24 de febrero de 1906): 2 y (22 de enero de 1907): 2. Presidió el municipio durante el "gobierno largo" del conservador Antonio Maura (en concreto de septiembre de 1907 a noviembre de 1909). Su renuncia fue muy lamentada por la corporación, que alababa sus muchas iniciativas en favor de la población. El Correo de Zamora (4 de septiembre de 1907): 2 y (19 de noviembre de 1909): 3. Sigue siendo concejal y posteriormente dirige de nuevo la corporación municipal durante parte del primer gobierno del conservador Eduardo Dato. Más tarde figura como administrador de Consumos. AMA, lib. 233, fol. I4v.

24. AHPZa, Fondo antiguo, leg. 305, exp. 3 y leg. 369, exp. 3. La tradición oral local atribuye a los Corcobado el préstamo de capital a un alto interés, aunque este aspecto no ha podido ser corroborado documentalmente. De hecho, en los protocolos notariales su presencia, no muy frecuente, se limita a la compraventa de fincas rústicas en Alcañices y su entorno. Entrevista con M. C. (2019); AHPZa, Protocolos notariales, libs. 13727-13732. 


\section{DOI: https://doi.org/10.22201/iie.18703062e.2021.119.2766}

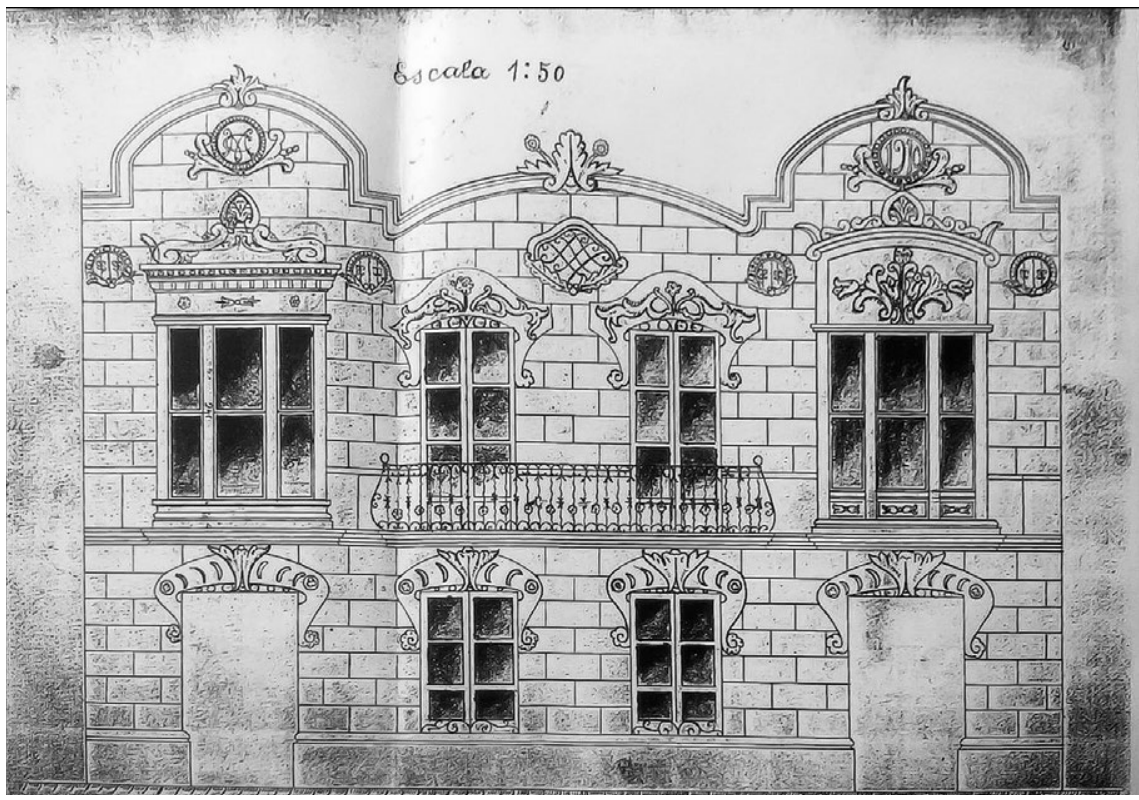

4. Francisco Ferriol, "Proyecto de vivienda para Manuel Corcobado en Alcañices (alzado)", I9ıo. Archivo de la Familia Carrión.

promotor de la vivienda. No será, sin embargo, hasta el padrón de I92I-1922 cuando aparezca Manuel Corcobado Losada como propietario de la finca. ${ }^{25}$ Tanto en el alzado que hemos podido consultar como en la fachada finalmente construida despunta la $\mathrm{M}$ inicial de su nombre de pila, acompañada en el proyecto por la $\mathrm{C}$ de su apellido (figs. 4 y 5 ). Esta última se cambió por una A, quizá de su cónyuge, en el resultado final. ${ }^{26}$ Aunque en el alzado y en la fachada actual conste el año de I9IO, fecha indudable de redacción del proyecto, la construcción de la vivienda se prolongó por lo menos hasta

25. Florentino Corcobado está registrado como propietario de diez fincas urbanas en la villa. Por su parte, la madre del promotor, Rita Losada Fraile, también consta como propietaria. AMA, caja IO2, carpetas I y I5.

26. Las iniciales del promotor en la fachada, que aparecen con cierta frecuencia en la arquitectura de las clases altas europeas, desempeñan la misma función que los antiguos blasones nobiliarios: son un símbolo de identidad familiar. Peter Burke, "La historia social y cultural de la casa”, Historia Crítica, núm. 39 (2009): I4, https://revistas.uniandes.edu.co/doi/abs/ı0.7440/ histcrit39.2009.02 (consultado en junio de 2020). 


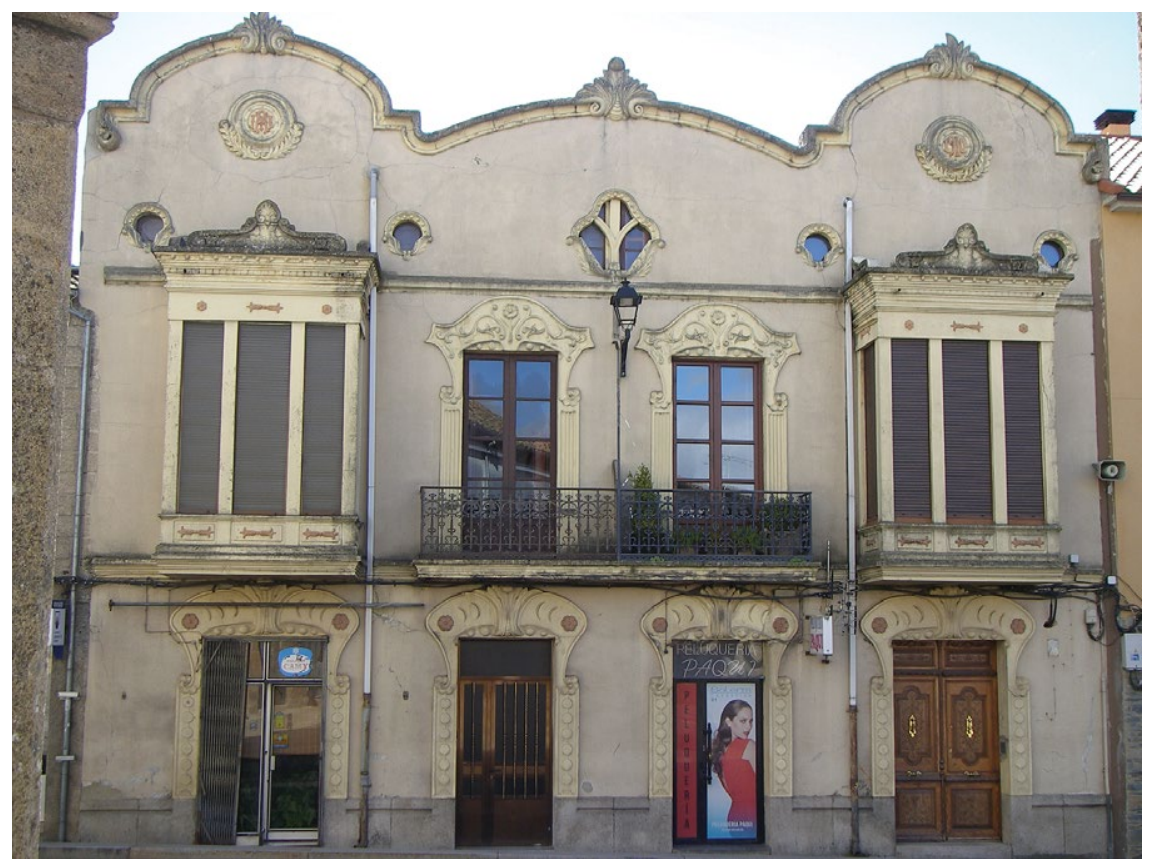

5. Aspecto actual de la casa Corcobado en Alcañices, fachada principal. Foto del autor.

I9II, pues en abril de I9II el promotor fue autorizado por parte del ayuntamiento para el acopio en la plaza mayor de materiales con destino a la construcción de su casa. ${ }^{27}$

A pesar de que no disponemos del proyecto completo signado por el autor, la fachada de la vivienda presenta buena parte de los estilemas habituales en la obra del arquitecto barcelonés, que describiremos más adelante. ${ }^{28}$ En este sentido, Ferriol ya había trabajado antes para la burguesía zamorana, asentada sobre todo en la capital de la provincia, y construyó los inmuebles modernistas más significativos. Tocaba ahora hacerlo, de manera semejante, para esta burguesía rural.

27. AMA, lib. 23I, fol. I3v.

28. Álvaro Ávila de la Torre, "La permeabilidad entre el modernismo y el eclecticismo en Zamora. Ejemplo de la indefinición y la dificultad en la clasificación estilística de la arquitectura entre los siglos XIX y Xx", Stvdia Zamorensia, núm. IX (20I0): I08, https://dialnet.unirioja.es/ ejemplar/295640 (consultado en junio de 2020). 


\section{DOI: https://doi.org/10.22201/iie.18703062e.2021.119.2766}

\section{Descripción del inmueble}

La fachada de la vivienda está concebida con un claro carácter escenográfico que busca proyectar una imagen de poder de su propietario. A diferencia de muchos de los inmuebles residenciales de Ferriol en la ciudad de Zamora, donde el arquitecto trabajó con superficies un tanto angostas, ahí lo generoso del solar entre medianeras le permitió trazar una fachada caracterizada por la simetría (fig. 4). Este hecho y el juego de formas rectas y curvas que combina el proyectista desembocan en un elegante resultado. ${ }^{29}$

Se compone la fachada de planta baja con vanos de acceso a las viviendas y locales comerciales; una primera planta muy noble, con miradores en los extremos y una balconada central, así como un desván iluminado por cinco óculos, todos circulares menos el lobulado central. Rematan la obra los característicos piñones curvos tan gratos al técnico barcelonés (fig. 5).

La ornamentación presenta elementos de forma sinuosa, recurrentes en la obra del arquitecto en la ciudad de Zamora: guardapolvos curvos con decoración vegetal, como en las casas de Valentín Matilla (I9II) y Tejedor (I9I3); también en la casa Matilla aparece el ventanal geminado del sobrado que podemos contemplar en Alcañices; tondos con guirnaldas, al estilo de los que se abren en el edificio levantado entre la calle Traviesa y la plaza del Mercado; áticos curvos, como en las viviendas de Crisanto Aguiar (1908) y la mencionada de Matilla, mientras que los miradores están emparentados con los de la casa de Gregorio Prada (I908). Sin olvidar la excelente forja de los balcones, similar a las obras capitalinas. ${ }^{30}$

29. El análisis del alzado de la fachada nos permite conocer mejor el método de trabajo del arquitecto (fig. 4), que ofreció al cliente la posibilidad de escoger entre dos modelos de miradores. Sabemos por otros ejemplos de promoción privada que los proyectos de Ferriol para particulares eran muy escuetos, pues se limitaban a definir los materiales de la estructura, cerramientos y acabados. Eso sí, los alzados eran vistosos, ya que utilizaba el color y enfatizaba determinadas líneas mediante el grosor. María Ascensión Rodríguez Esteban, "La redacción técnica y los dibujos de los proyectos de las construcciones modernistas y eclécticas de Zamora”, Stvdia Zamorensia, núm. XII (2013): 197-217, https://dialnet.unirioja.es/ejemplar/383IOI (consultado en junio de 2020). Parece que éste no es el caso examinado, poco esmerado. Tal vez porque se trate tan sólo de un alzado esquemático para permitir al cliente escoger el tipo de mirador.

30. Parece que la adopción del mirador como elemento muy presente en sus obras es una peculiaridad de la etapa zamorana, probablemente por adaptación al clima, ya que no aparece en la producción barcelonesa. Ávila, "Francesc Ferriol”, 245-249. 
Esta obra de Alcañices (1910-I9II) se encuentra cronológicamente entre las casas de Aguiar y Prada (I908), Matilla (I9II) y Tejedor (I9I3), aunque quizá sea la Casa Matilla (casi coetánea) con la que más parentesco estilístico guarda. No obstante, la decoración en Alcañices es algo más plana y contenida que en las obras zamoranas de Ferriol, de por sí más comedidas que los ejemplos de su anterior producción barcelonesa. ${ }^{3 \Gamma}$

El edificio muestra en muchos aspectos un carácter dual. En primer lugar, cuenta con una parte residencial, burguesa, y un edificio auxiliar para el servicio. Estas dos partes han sido históricamente habituales en las casas de las élites europeas: una parte delantera, residencial o de prestigio, y una parte trasera dedicada a las faenas domésticas y al alojamiento de aquellos encargados de desempeñarlas. ${ }^{32}$ La primera, en este caso, puede definirse como arquitectura "culta" y la segunda comparte las características de la construcción popular.

El área residencial, a su vez, dispone de la descrita fachada principal, de raigambre urbana, construida en ladrillo revocado y con elementos ornamentales prefabricados; de carácter cerrado y representativo, como si fuera un telón (fig. 5). Mientras que la fachada trasera, formada por galerías superpuestas con pies de madera, acredita un talante más abierto, aun cuando también se trata de una tipología arquitectónica ajena a la comarca (fig. 9).

Las diferencias también se plantean en los materiales constructivos. De manera novedosa respecto a la arquitectura local, se utilizaron en la zona burguesa elementos metálicos, tanto en forma de columnas de fundición (fig. 6) como de viguería con perfil de doble $\mathrm{T}$ que sustenta las bovedillas de rasilla (fig. 7). ${ }^{33}$ Por su parte, el edificio auxiliar para el servicio emplea los materiales de la arquitectura vernácula: mampostería de pizarra, cantería en vanos, cargaderos de madera y tabiques interiores con entramado de madera y adobe (fig. 8).

31. Ávila, "Francesc Ferriol", 245-249.

32. Burke, "La historia social", I3.

33. En los primeros proyectos que planteó en la ciudad de Zamora, Ferriol usó el hierro tan sólo para los forjados de las repisas y de los techos de los sótanos. A partir del Teatro Nuevo (I9II) utiliza con más frecuencia este material: vigas y viguetas de doble $\mathrm{T}$, y columnas circulares de fundición. María Ascensión Rodríguez Esteban, "El tratamiento estructural en la arquitectura modernista de Zamora: la paulatina introducción del hierro y su consolidación”, en Santiago Huerta Fernández, Ignacio Javier Gil Crespo, Miguel Taín Guzmán y Santiago García Suárez, eds., Actas del Séptimo Congreso Nacional de Historia de la Construcción (Madrid: Instituto Juan de Herrera, 20II), II99-I200, http://www.sedhc.es/biblioteca/paper.php?id_p=745 (consultado en junio de 2020). 


\section{DOI: https://doi.org/10.22201/iie.18703062e.2021.119.2766}

4I6 JOSÉ LUIS HERNÁNDEZ LUIS

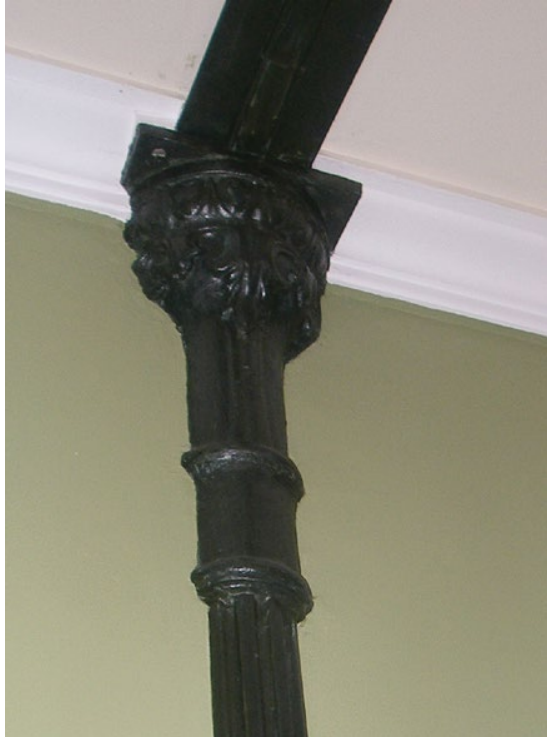

6. Columna de fundición en el interior de la vivienda. Foto del autor.

La zona residencial se articula en torno a un núcleo central formado por un patio de luces y una escalera, también utilizados por el tracista en Zamora, y es habitual en las viviendas del ensanche barcelonés que proyectó. ${ }^{34} \mathrm{Al}$ menos una de las dos viviendas en las que está dividido el inmueble actualmente conserva en buena parte la distribución original, que describiré a continuación.

Para aprovechar el desnivel del terreno se dispuso en el semisótano una cocina matancera dividida en varias estancias, una de ellas utilizada como cuarto para la sal. Separado de este ámbito por una verja sobre un murete se encuentra el huerto o jardín, donde un pozo recoge las aguas pluviales que provienen del patio de luces. Todavía son visibles los restos de la red de desagües que se diseñó para la casa, inexistentes por aquellos años en el resto de la población.

En la planta baja encontramos otra vez la dualidad de la que hablaba, en este caso entre lo público y lo privado, representados por un despacho a la plaza (accesible desde el vestíbulo), opuesto a la cocina y al comedor (abiertos hacia el huerto-jardín trasero). El mismo contraste público/privado aparece en la primera planta, pues el salón está orientado hacia la plaza, y coincide con el mirador y el balcón, mientras que a una de las galerías traseras asoma

34. Ávila, "Francesc Ferriol", 252. 


\section{DOI: https://doi.org/10.22201/iie.18703062e.2021.119.2766}

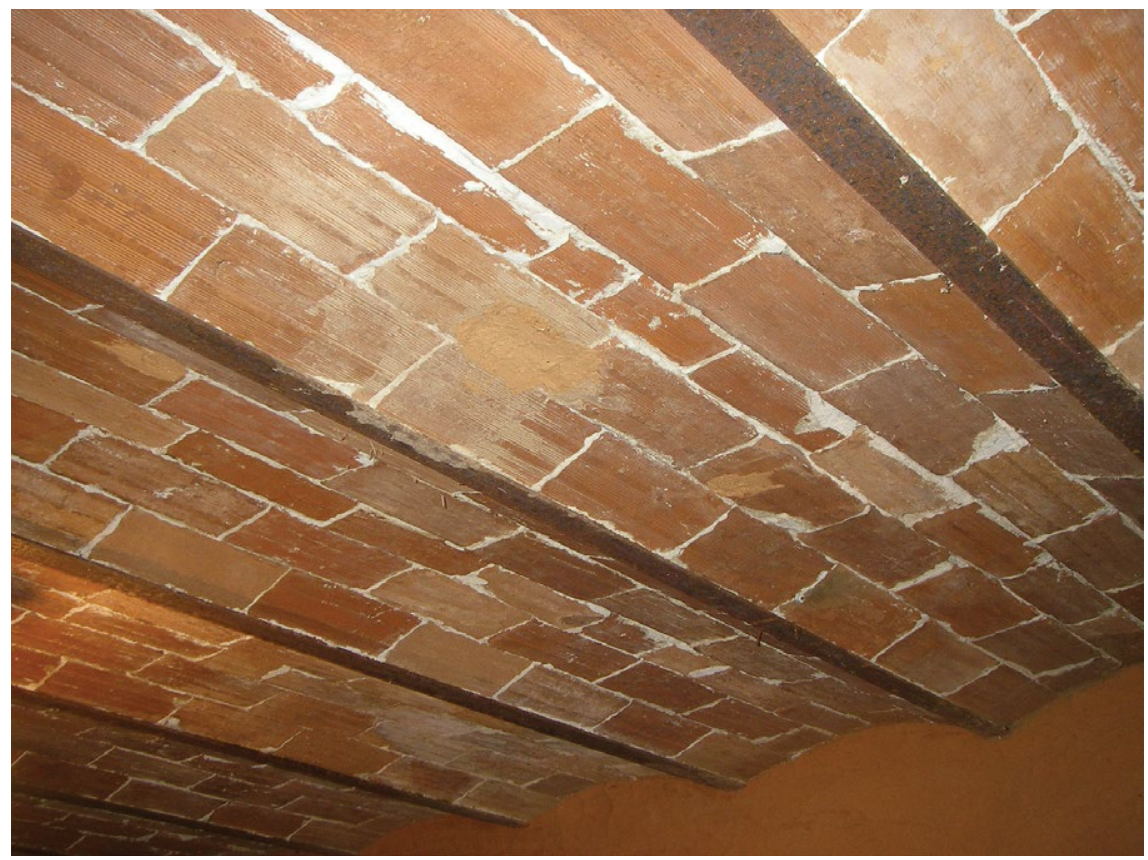

7. Viguería con perfil de doble T que sustenta las bovedillas de rasilla. Foto del autor.

el dormitorio principal. Por su parte, el edificio auxiliar para alojamiento del servicio doméstico y almacenamiento de productos agrarios comunica con la vivienda burguesa a través de la mentada cocina.

No sólo el aspecto exterior de la casa confería distinción a sus habitantes. También lo hacían las comodidades con que contaba la vivienda, enclavada en un entorno rural que carecía de ellas. La construcción del inmueble es un poco posterior a la llegada del fluido eléctrico a la villa (I910), iniciativa del comerciante Manuel Calvo Casado. ${ }^{35}$ Parece que la vivienda contó desde el comienzo con iluminación eléctrica; los propietarios actuales conservan, aunque desmontadas, algunas de las elegantes lámparas originales.

35. AMA, lib. 230, fols. 24, 27, 29 y 36r. Es posible que el arquitecto interviniera en la fábrica de electricidad construida a 200 metros del entonces casco de la villa. El edificio, actualmente en ruinas, exhibe una molduración de los vanos que guarda cierta relación con los de la escuela diseñada por Ferriol. 
DOI: https://doi.org/10.22201/iie.18703062e.2021.119.2766

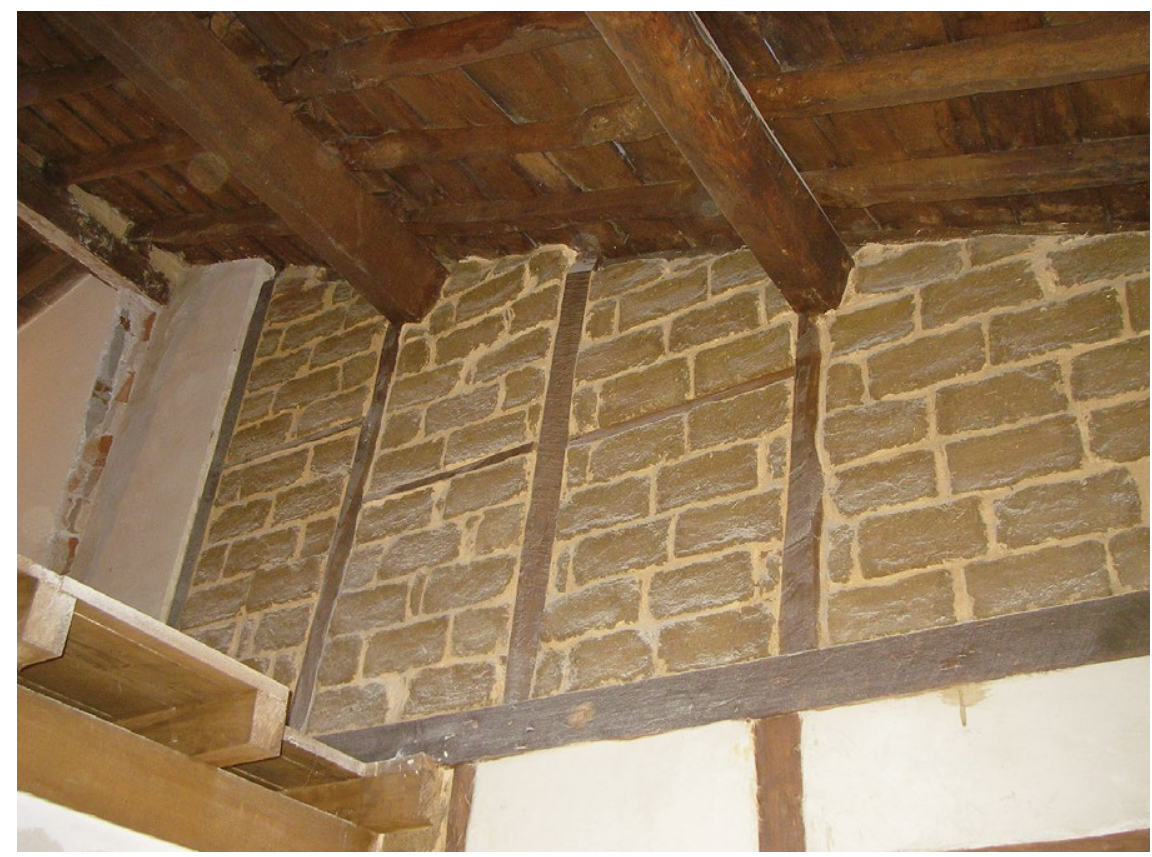

8. Tabiques interiores con entramado de madera y adobe en el edificio auxiliar. Foto del autor.

Para calentar la casa se disponía de varias chimeneas prefabricadas, de hierro fundido (fig. IO), con portezuela y depósito para recoger cómodamente las cenizas. No paraban ahí las comodidades de la casa, pues por lo menos un banco de hierro fundido y madera fue instalado en el huerto-jardín, cuyos soportes aún se conservan, señal inequívoca de que este espacio servía para solaz de los residentes, así como para el cultivo de frutas y verduras.

\section{Proyectos de prisión-juzgado y nuevo mercado}

La intervención de Ferriol en Alcañices no se limitó al edificio escolar y a la residencia de los Corcobado. Proyectó otras dos construcciones, una prisión-juzgado y un mercado que, de haberse hecho realidad, hubieran cambiado la situación de las infraestructuras públicas en la comarca y, con ello, de la imagen proyectada por la administración. Este carácter representativo es 


\section{DOI: https://doi.org/10.22201/iie.18703062e.2021.119.2766}

INTERVENCIONES DE FRANCISCO FERRIOL EN ALCAÑICES

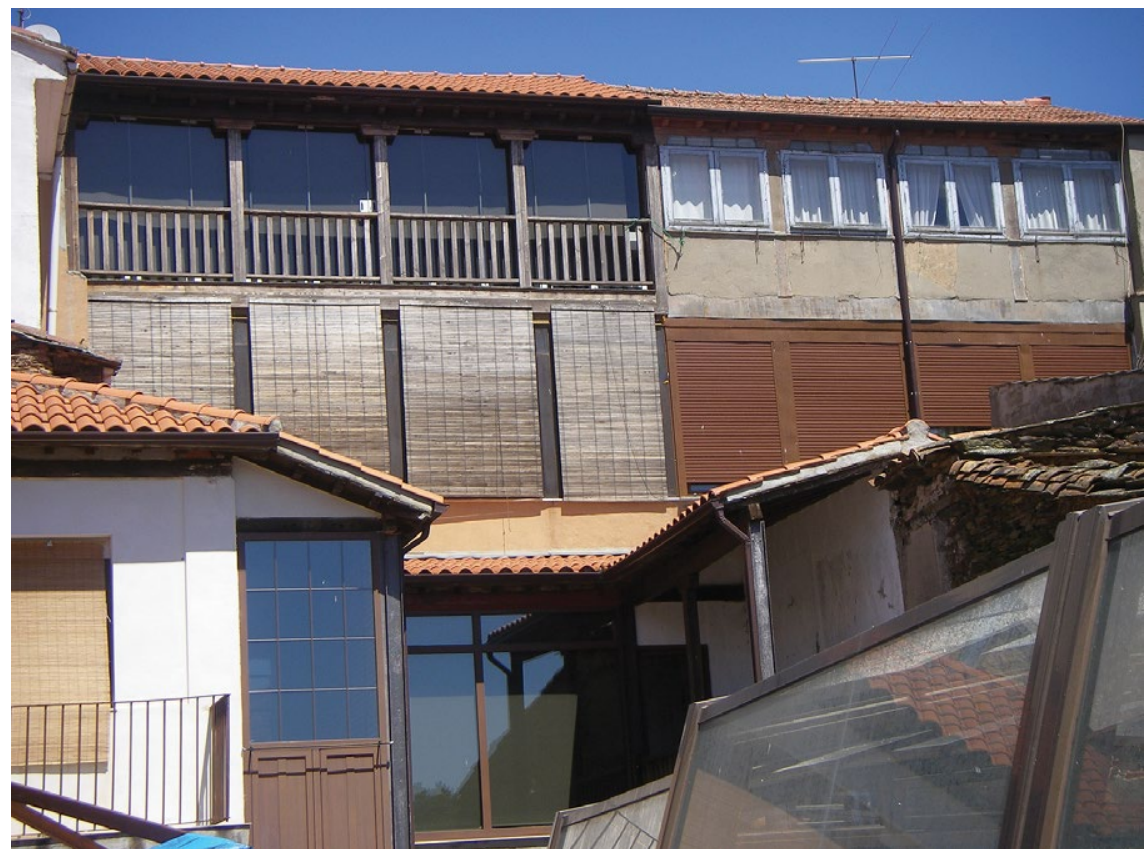

9. Galerías traseras de la Casa Corcobado en Alcañices. Foto del autor.

especialmente evidente en los edificios penitenciarios. La prisión, a juicio de Foucault, es la más poderosa herramienta de control y educación del individuo, ya que allí el Estado dispone de la libertad y del tiempo de la persona; de todas sus facultades físicas y morales. ${ }^{36}$

En la España de la Restauración el mal estado de las prisiones era la tónica. ${ }^{37}$ Diferentes intentos de mejora se vieron frenados por la falta de medios, aunque nos legaron una prolija legislación. No es, pues, mera coincidencia

36. Michel Foucault, Vigilar y castigar: nacimiento de la prisión (Madrid: Siglo XXI Editores, I994 [1975]), 238.

37. Así sucedía, por ejemplo, en la vecina provincia de León, cuyos establecimientos penitenciarios, instalados en casas consistoriales, particulares y conventos, se encontraban en deficiente situación higiénica y de seguridad. Benigno Castro, Historia de las cárceles leonesas. Memoria de veinte siglos de encarcelamiento y arquitectura penitenciaria (León: Everest-Sociedad Estatal de Infraestructuras y Equipamientos Penitenciarios), II9-I2O. 


\section{DOI: https://doi.org/10.22201/iie.18703062e.2021.119.2766}

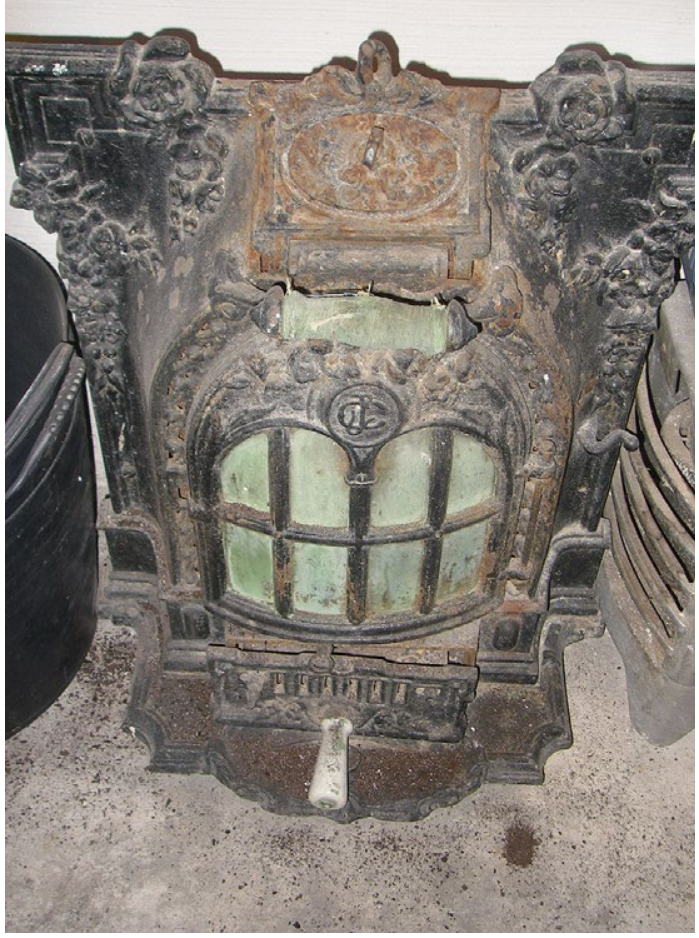

Io. Frente de chimenea de la vivienda, actualmente retirado. Foto del autor.

que el edificio que voy a referir coincida en el tiempo con el impulso que supuso la promulgación del real decreto del 5 de mayo de I9I3, que implantaba definitivamente el sistema penitenciario progresivo. ${ }^{38} \mathrm{El}$ real decreto estipulaba que los establecimientos penitenciarios enclavados en las cabeceras de partido judicial, como la de Alcañices, estaban destinados a prisión preventiva durante la substanciación del sumario, el cumplimiento de penas de arresto mayor de civiles, así como para la estancia accidental de reclusos transeúntes que iban a cumplir condena en otras prisiones, o la práctica de dili-

38. Esta normativa, impulsada por el jurista Fernando Cadalso Manzano, cierra una etapa de constantes reformas. Daniel Fernández Bermejo, "Del sistema progresivo a la individualización científica. La elaboración de la Ley General Penitenciaria y la relevancia del bienio 1978-1979 en el derecho penitenciario", Anuario de Derecho Penal y Ciencias Penales, núm. LXXII (2019): 500-50I, https://dialnet.unirioja.es/servlet/articulo?codigo=7059258 (consultado en septiembre de 2020). 
gencias judiciales (art. 20I). ${ }^{39}$ De ahí que la vinculación espacial de la prisión con el juzgado guardara su lógica.

Nuestro arquitecto trazó en I9I3 un recinto que había de acoger al mismo tiempo la prisión y el juzgado de partido, que fue aprobado por real orden en julio de 19I4. El costo calculado por Ferriol ascendía a 92,038 pesetas..$^{40}$ Planteó un conjunto formado por un pabellón delantero para el juzgado, de dos plantas, y dos pabellones laterales de una planta para la cárcel. Ésta disponía de varios patios, dos cocinas, centro de vigilancia, enfermería y celdas. El juzgado contaba, además, con una sala de autopsias. Todo el recinto estaba dotado de cuatro retretes, un depósito séptico y dos pozos ciegos.

El edificio se alzaría con muros de mampostería, ladrillo para vanos y pilares (todo ello revocado), mientras que la sillería se reservaba para el zócalo, impostas, cornisa y exteriores de los vanos. Probablemente por cuestiones presupuestarias, no llegó a construirse, de modo que el juzgado se instaló en dependencias de la casa consistorial y la prisión en el antiguo convento franciscano que todavía hoy se levanta al sureste de la villa. ${ }^{4 \mathrm{I}}$

Unos ańos antes, en el pleno del I7 de julio de 1909, el ayuntamiento había encargado al arquitecto de la escuela que formara el proyecto para un nuevo mercado en el llamado "Portal del Grano". ${ }^{42}$ En el pleno del I de noviembre de ese año se presentó el proyecto del nuevo mercado, presupuestado en 36,47I pesetas. Se acordó subastar la obra el 28 de noviembre, lo cual se anunció en el Boletín Oficial de la Provincia. ${ }^{43}$ Sin embargo, la obra no se llegó a ejecutar, pues en octubre de I9I4 se hacen reparaciones menores en el portal. ${ }^{44}$ Meses después, una demanda que interpone el arquitecto contra el municipio (abril de 1915) reclama el pago del proyecto, pero no menciona la dirección de obra. ${ }^{45}$

39. GM (II de mayo de I9I3): 4I8, https://www.boe.es/datos/pdfs/BOE//1913/13I/Aoo3970044I.pdf (consultado en septiembre de 2020).

40. AMA, caja 135 , carpeta 5 .

4I. Sí se llegaron a trazar las vías públicas que generó el proyecto de construcción, pues a principios de I9I5 se enajenaron las parcelas sobrantes. AMA, lib. 233, fols. I7V-I8r.

42. AMA, lib. 229, fol. 22r.

43. AMA, lib. 229, fol. $32 \mathrm{v}$. Lamentablemente, no se ha podido localizar el proyecto para analizar con más detalle las características arquitectónicas de la obra y su adecuación a la legislación y a los modelos de la época.

44. AMA, lib. 233, fol. Ior.

45. AMA, lib. 233 , fol. $22 \mathrm{v}$. 


\section{DOI: https://doi.org/10.22201/iie.18703062e.2021.119.2766}

\section{Conclusiones}

La suerte corrida por los edificios públicos proyectados por Francisco Ferriol en Alcañices pone de manifiesto las dificultades del Estado en la España del siglo XIX y buena parte del Xx, para dotarse de instalaciones adecuadas a sus funciones. Los proyectos de la escuela y de la cárcel-juzgado que hemos revisado muestran cómo a menudo se dispuso tanto de una normativa avanzada como de profesionales preparados. Mas la inestabilidad política y, sobre todo, la falta de recursos económicos frenó su alcance. Los resultados revelan bien a las claras los inconvenientes habidos en Espańa para construir desde el punto de vista arquitectónico una imagen moderna, atractiva y respetable del Estado, factor a tener en cuenta a la hora de analizar los problemas de construcción nacional que todavía le aquejan. ${ }^{46}$

El proyecto de la escuela es anterior en unos meses a la divulgación oficial de la colección de modelos elaborada por el arquitecto Luis Domingo de Rute para facilitar a los municipios la construcción de edificios docentes. No obstante, se da una notable coincidencia con el modelo número siete, que planteaba un esquema lineal y simétrico, con pabellones transversales y un cuerpo central. Por ello, es posible que Ferriol fuera asesorado desde el Negociado de Arquitectura Escolar, creado en 1904. ${ }^{47}$ El edificio finalmente construido responde, empero, a un modelo bastante frecuente en la época, importado de Francia..$^{48}$

El análisis de la Casa Corcobado, por su parte, evidencia la utilización de la vivienda como elemento de diferenciación social, de construcción de una identidad de grupo, merced al empleo de una arquitectura moderna de origen

46. José Álvarez Junco, Mater dolorosa. La idea de España en el siglo XIX (Madrid: Taurus, 200I). 47. Francisco Javier Rodríguez Méndez, "Luis Domingo de Rute, arquitecto de modelos para la construcción de escuelas públicas en España a comienzos del siglo xx", Historia de la Educación, núm. 38 (2019): 269, 271 y 275-276, https://revistas.usal.es/index.php/0212-0267/ article/view/ hedu201938257276/2233I (consultado en septiembre de 2020).

48. Un inmueble tripartito y simétrico, con un cuerpo central de dos plantas (la superior para viviendas), y dos alas para las clases. Desde la Francia decimonónica este modelo se extendió por diversos países. Buena prueba de ello es el cercano edificio escolar de Miranda do Douro (Portugal), también alzado a principios del siglo xx. Francisco Javier Rodríguez Méndez, "La arquitectura escolar espańola del primer tercio del siglo xx, vista desde Castilla y León", Artigrama, núm. 34 (2019): I88, http://www.unizar.es/artigrama/html_dig/34.html (consultado en septiembre de 2020). 
urbano en un entorno rural y tradicional. Una forma de amplificar este mensaje es recurrir en la casa a formas y materiales no habituales hasta entonces en el entorno. Se trataba de transmitir distinción al emplear un estilo ornamental de moda, el modernismo, asociado a la burguesía, y recurrir a materiales de construcción como el hierro fundido, sinónimo de progreso a lo largo de todo el siglo XIX. La vivienda se convierte, así, en marco de nuevas y diferentes formas de vida, asociadas a comodidades como la electricidad, el agua corriente, etc. Y se dota al resultado de gran visibilidad social mediante el emplazamiento en un lugar tan representativo como la plaza mayor. El caso analizado nos demuestra cómo la llegada de la modernidad al mundo rural estuvo muy ligada a reducidas élites políticas (administración); económicas (comercio) e intelectuales (profesiones liberales), de extracción urbana o que buscaban imitar la vida en la ciudad.

Por lo que atañe al juzgado-prisión, se constata la inexistencia de un paradigma arquitectónico único, a pesar de que el referente por antonomasia, tanto en España como en el resto del mundo, fuera el diseño radial inspirado en el panóptico de Bentham. ${ }^{49}$ Sin embargo, parece que el modelo de edificio delantero ocupado por el juzgado y uno o varios pabellones traseros para cárcel fue bastante habitual, como pone de relieve, entre otros ejemplos, el conjunto construido en Bermillo de Sayago (Zamora), partido judicial vecino al de Alcañices. A partir del recinto sayagués, diseñado por Segundo Viloria pocos años antes de que Ferriol firmase su proyecto, podemos hacernos una idea aproximada del aspecto exterior de este tipo de conjuntos (fig. II).

En cuanto al arquitecto, descubrimos en estos proyectos a un Ferriol pragmático y ecléctico, que se ceñía al gusto o al presupuesto del comitente, así como a los modelos de prestigio, sin desprenderse de la formación clásica (tendencia a la simetría $)^{50}$ y utilizando el modernismo fundamentalmente como

49. Pedro Oliver Olmo, Luis Gargallo Vaamonde y Jesús Carlos Ursa Lozano, "Panoptismo sin panóptico. La arquitectura penitenciaria en la España contemporánea”, en ed. Carmen Ortiz García, Lugares de represión, paisajes de la memoria. Aspectos materiales y simbólicos de la Cárcel de Carabanchel (Madrid: Los Libros de la Catarata, 2013), 138; Manuel L. Ruiz-Morales, "La arquitectura penitenciaria como representación del castigo. Las maneras de comprender la pena de prisión en la historia", Política Criminal, núm. 29 (2020): 422, http://politcrim.com/wpcontent/uploads/2020/07/Voli5 N29Ais.pdf (consultado en septiembre de 2020).

50. Fernández Alba afirma que el equilibrio de masas, la simetría de la composición y la pro- 
DOI: https://doi.org/10.22201/iie.18703062e.2021.119.2766

424

JOSÉ LUIS HERNÁNDEZ LUIS
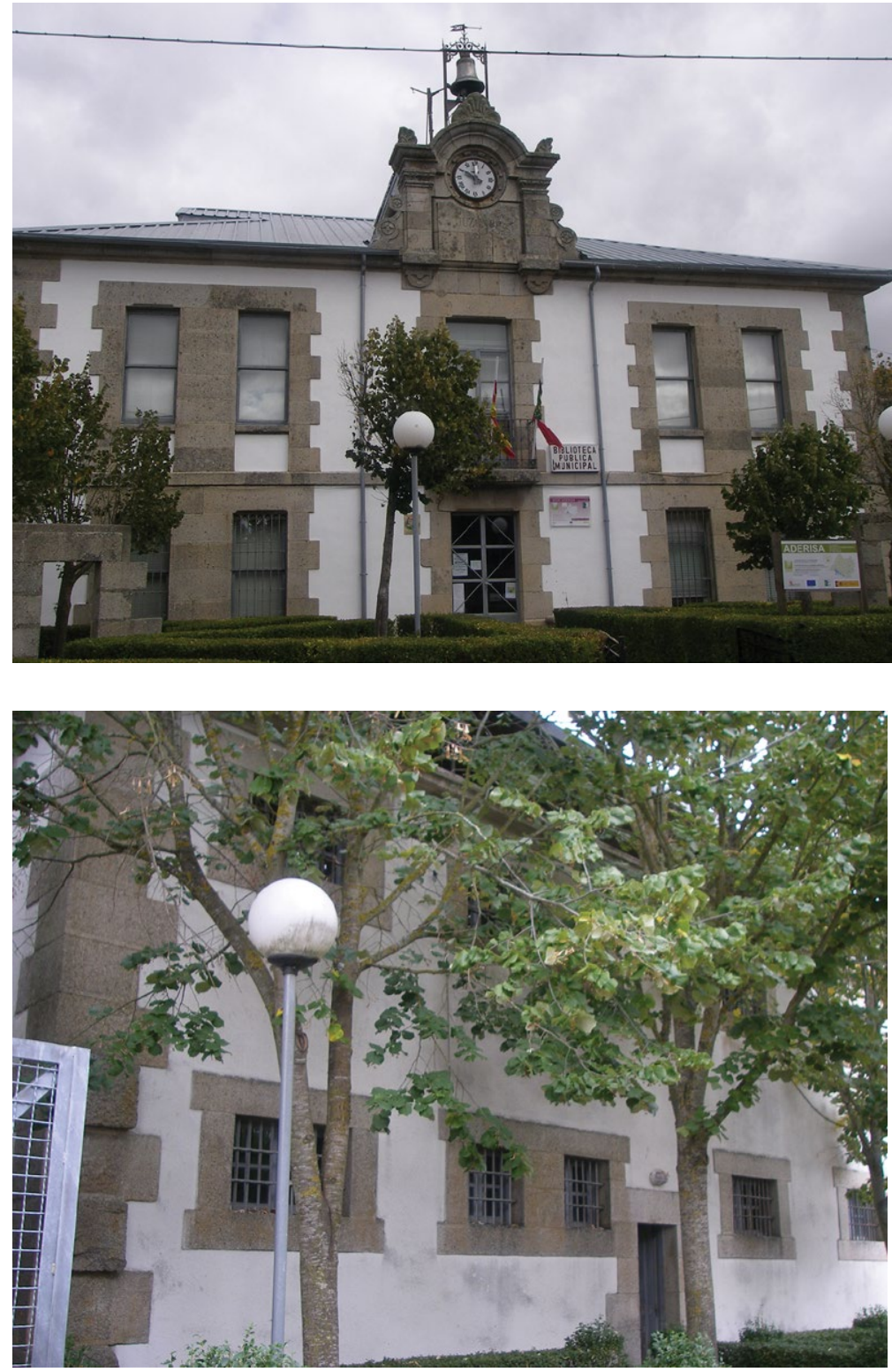

II. Antiguo juzgado y cárcel de partido en Bermillo de Sayago. Fotos del autor. 
repertorio ornamental. ${ }^{\text {s }}$ En este sentido, su obra en Alcañices resultará más comedida que la proyectada al inicio de su carrera en Barcelona o en la propia capital zamorana. is

porción en el ritmo de los diferentes elementos arquitectónicos de la fachada eran presupuestos ideológicos básicos en la formación de los arquitectos de esta época. Antonio Fernández Alba, "Aprendizaje y práctica de la arquitectura en España", en Spiro Kostof, coord., El arquitecto: historia de una profesión (Madrid: Cátedra, 1984 [1977]), 308.

5I. No se muestra como el técnico más libre en las obras públicas, sino bastante más contenido, como sucedió en la escuela de Alcañices o en sus coetáneos Laboratorio Municipal de Zamora (1909) y teatro Ramos Carrión (I9II). Véase Ávila, "Francesc Ferriol”, 248 y 254. Según este autor, Ferriol tenía una comprensión y asimilación íntegra del estilo. Sin embargo, el mismo historiador es consciente de que no toda la obra de Ferriol es modernista, como ponen de relieve el teatro Ramos Carrión y el Laboratorio Municipal de Zamora, quizá el edificio más relacionado con el grupo escolar. Ávila, "La permeabilidad", 96 y I09.

N.B. Mi agradecimiento a Cristina Aguiar, Tońi Turiel (†), Martina Carrión, Ana Mota y Eva B. Carro por la ayuda prestada durante la investigación. 